\title{
Root Canal Morphologies of Mandibular Premolars in Southeast Anatolian Population: Evaluation of CBCT
}

\begin{abstract}
SUMMARY
Background/Aim: This study aimed to evaluate the root canal morphology of mandibular first and second premolars with the aid of conebeam computed tomography (CBCT) in the Southeast Anatolian population. Material and Methods: The study examined a total of 1258 mandibular first and second premolars using cone-beam computed tomography images of 370 randomly selected patients who applied to the Department of OralDental and Maxillofacial Radiology of Faculty of Dentistry, Dicle University due to various indications. The total number of roots and root canals, canal symmetry and correlations between the right and left side of the mandible, and the prevalence in men and women were recorded. Data was analzyed using the Chi-Square and Fisher's Exact tests. Canal configurations were evaluated based on the Vertucci classification. Results: The evaluation of CT images of a total of 370 individuals showed that $88.89 \%$ of the first premolars and $98.45 \%$ of the second premolars were symmetrical. The canal anatomy of the first premolars suggested that $85.98 \%$ of the premolars were of Type I, 12.02\% were of Type V, and $2 \%$ were of Type III based on the Vertucci classification. On the other hand, the canal anatomy of the second premolars revealed that $98.83 \%$ were of Type $I, 0.67 \%$ were of Type $V$, and $0.5 \%$ were of Type III. Conclusions: The prevalent morphology of the multiple canals was Type $V$, except for the Vertucci classification Type I in the mandibular first premolars. Limited number of canal variations were observed in the mandibular second premolars.
\end{abstract}

Key words: Mandibular Premolars, Vertucci Classification, CBCT
Güney Mustafa Yüzer, Sadullah Kaya

Department of Endodontics, Dicle University, Diyarbakır, Turkey

\section{ORIGINAL PAPER (OP)}

Balk J Dent Med, 2022;22-26

\section{Introduction}

Clinicians need to know root anatomy and variations of root canal morphology to perform a successful root canal treatment. It may lead to the failure of endodontic procedure when one of the canals of the root canal system is missed during treatment ${ }^{1}$. Mandibular premolars have many root or canal variations; therefore, endodontic therapies are among the most difficult treatment methods to perform ${ }^{2}$. The incidence, location and morphology of root canal systems may vary from one ethnic or regional population to other populations.

Many researchers examined the configurations of root canal systems using various methods and reported anatomical variations related to mandibular premolars ${ }^{3}$. Most studies reported one root and one root canal for mandibular premolars ${ }^{4}$. However, other studies showed that the mandibular premolars had more than one root canal. In 1973, Green identified that $8 \%$ of the mandibular second premolars and $14 \%$ of the mandibular first premolars had more than one root canal; however, Vertucci stated that $2.5 \%$ of the mandibular second premolars and $30 \%$ of the mandibular first premolars had more than one root canal ${ }^{4,5}$.

Conventional radiography, hard tissue section, and root canal dyes or in vitro micro-CT scan are commonly used methods to determine the configuration of root canals. Conventional images compress three-dimensional 
(3D) anatomy into a two-dimensional view, leading to displaying some important features of a tooth and its surrounding tissues only in the mesiodistal plane. Therefore, the features which are presented in the buccolingual dimension may not be thoroughly evaluated. Cone-beam computed tomography (CBCT) scan was introduced into the field of endodontics in $1990^{6}$. The non-invasive three-dimensional imaging technique is used in many endodontic applications, including morphological evaluations ${ }^{7}$. Various studies on root canal morphology in maxillary and mandibular first molars were performed using CBCT. The results suggested that the application of CBCT was beneficial in identifying variations of the canal configuration $^{8,9}$.

This study aimed to investigate the prevalence of root anatomy and complex root canal morphology of mandibular premolars in the Southeast Anatolian population.

\section{MaterIal and Methods}

In the study, CBCT images of 370 patients, who applied to the Department of Oral-Dental and Maxillofacial Radiology of Faculty of Dentistry, Dicle University between 2018 and 2020, were used. Selection of images was performed according to the following criteria:

1. Diagnostically sufficient level of image quality of mandibular first and second premolars

2. Complete root development of relevant teeth

3. No root resorption, calcification or periapical lesions

4. No root canal fillings, posts or crown restorations
CBCT images were obtained using an $\mathrm{iCAT}{ }^{\circledR}$ CBCT device (Model 17-19, Imaging Sciences International, Hatfield, $\mathrm{Pa}$ ) with an $\mathrm{x}$-ray tube rotating 360 degrees and a voxel size of $0.3 \mathrm{~mm}$. All CBCT scans were performed according to the manufacturer's standard settings $(120 \mathrm{kV}$, $5 \mathrm{~mA}$, exposure duration of $9.6 \mathrm{~s}$, and axial thickness of $0.3 \mathrm{~mm}$ ), and exposure parameters were kept stable for each scan. The images obtained were evaluated in three planes (sagittal, axial, and coronal) using iCATVision (Imaging Sciences International, Hatfield, PA) software.

Personal data, including age and gender, was recorded for all patients. The classification was made according to the Vertucci classification by studying tooth position, number of roots, canal configuration, and number of canals. The study data were analyzed using the SPSS (IBM) version 21.0 software. Descriptive statistics were used to express the variables in the study. The ChiSquare Test was used to analyze the relationships between the groups of nominal variables. When the expected values in the cells of the $2 \times 2$ tables did not have sufficient volume, Fisher's Exact Test was used. A $p$ value of 0.05 was considered significant.

\section{Results}

Of total 370 participants, 197 (53.24\%) were female and $173(46.76 \%)$ were male, aged 15 to 70 years. Based on the classification of age groups, it was observed that $16.76 \%$ of the participants were at the age of $\leq 20$, $25.14 \%$ were at the age of 21 to $30,19.73 \%$ were at the age of 31 to $40,16.49 \%$ were at the age of 41 to 50 , $14.32 \%$ were at the age of 51 to 60 , and $7.57 \%$ were at the age of 61 to 70 . A total of 655 mandibular first premolars and 603 mandibular second premolars were evaluated (Table 1).

Table 1. Root Canal Classification of First and Second Premolar Teeth

\begin{tabular}{|c|c|c|c|c|c|c|}
\hline & No. Of teeth & Type I & Type III & Type V & Two Roots & Three Roots \\
\hline \multicolumn{7}{|c|}{ First Premolar, n(\%) } \\
\hline \multicolumn{7}{|c|}{ Gender } \\
\hline Male & 309 & $257(84.82)$ & $7(2.31)$ & $39(12.87)$ & $6(1.94)$ & - \\
\hline Female & 346 & $301(86.99)$ & $6(1.73)$ & $39(11.27)$ & - & - \\
\hline Total & 655 & $558(85.98)$ & $13(2)$ & $78(12.02)$ & $6(0.92)$ & - \\
\hline \multicolumn{7}{|c|}{ Second Premolar, n(\%) } \\
\hline \multicolumn{7}{|c|}{ Gender } \\
\hline Male & 287 & $279(98.24)$ & $3(1.06)$ & $2(0.7)$ & $2(0.7)$ & $1(0.35)$ \\
\hline Female & 316 & $314(99.37)$ & - & $2(0.63)$ & - & - \\
\hline Total & 603 & $593(98.83)$ & $3(0.5)$ & $4(0.67)$ & $2(0.33)$ & $1(0.17)$ \\
\hline
\end{tabular}


When the root canal anatomy of the first premolars was analyzed according to the Vertucci classification, it was observed that $85.98 \%$ were of Type I, $2 \%$ were of Type III, and $12.02 \%$ were of Type V. On the other hand, it was identified that $99.08 \%$ of the premolars had one root and $0.92 \%$ had two roots (Figure 1 ).

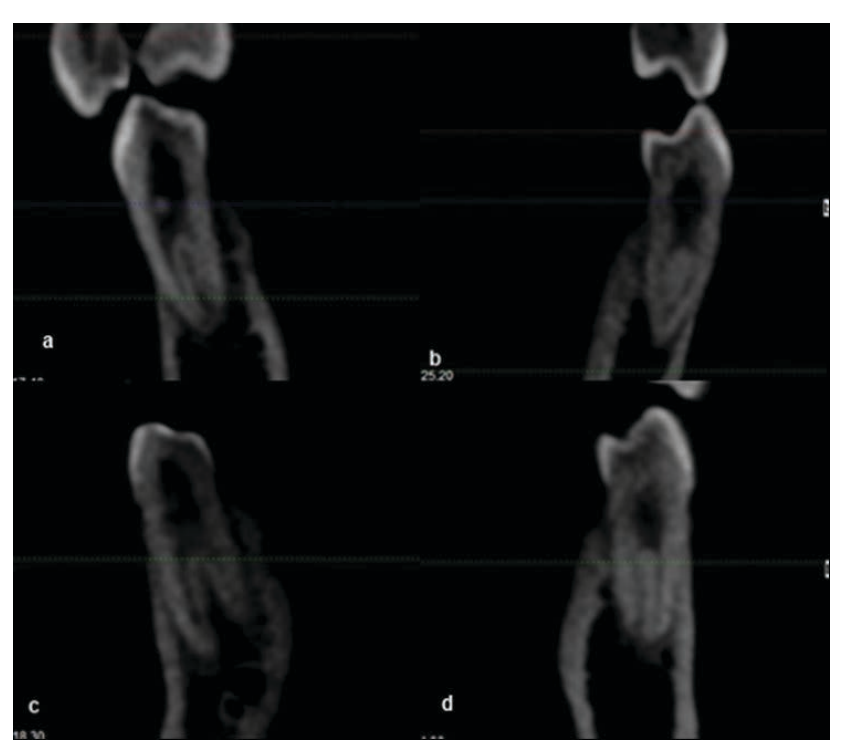

Figure 1. Sagittal plan. (a-b)Type III. (c) Two Roots Premolar. (d) Type V.

When the second premolars were studied according to the Vertucci classification, it was observed that $98.83 \%$ were of Type I, $0.5 \%$ were of Type III, and $0.67 \%$ were of Type V. In the analysis of the number of roots, one root was identified in $99.5 \%$ of the premolars, while the rates were $0.33 \%$ and $0.17 \%$ for two roots and three roots, respectively (Figure 2).

It was observed that $88.89 \%$ of 297 mandibular first premolars and $98.45 \%$ of 258 mandibular second premolars were symmetrical. There was no statistically significant relationship between the gender and age groups in the symmetrical premolars ( $\mathrm{p}>0.05)$.

Root canal types of mandibular first premolars were evaluated according to age, and statistically a significant difference was determined between age groups $(\mathrm{p}<$ $0.05)$. While the root canal classification of $81.3 \%$ of the participants at the age of $\leq 20,77.27 \%$ of those at the age of 21 to $30,88.1 \%$ of those at the age of 31 to $40,92.23 \%$ of those at the age of 41 to $50,96.39 \%$ of those at the age of 51 to 60 , and $94.74 \%$ of those at the age of $\geq 61$ were of Type I, and $1.63 \%$ of those at the age of $\leq 20,3.41 \%$ of those at the age of 21 to $30,1.59 \%$ of those at the age of 31 to $40,2.41 \%$ of those at the age of 51 to 60 and $2.63 \%$ of those at the age of of $\geq 61$ were of Type III. Moreover, $17.07 \%$ of the participants at the age of $\leq 20,19.32 \%$ of those at the age of 21 to $30,10.32 \%$ of those at the age of 31 to $40,7.77 \%$ of those at the age of 41 to $50,1.2 \%$ of those at the age of 51 to 60 , and $2.63 \%$ of those at the age of $\geq 61$ were of Type $\mathrm{V}$.

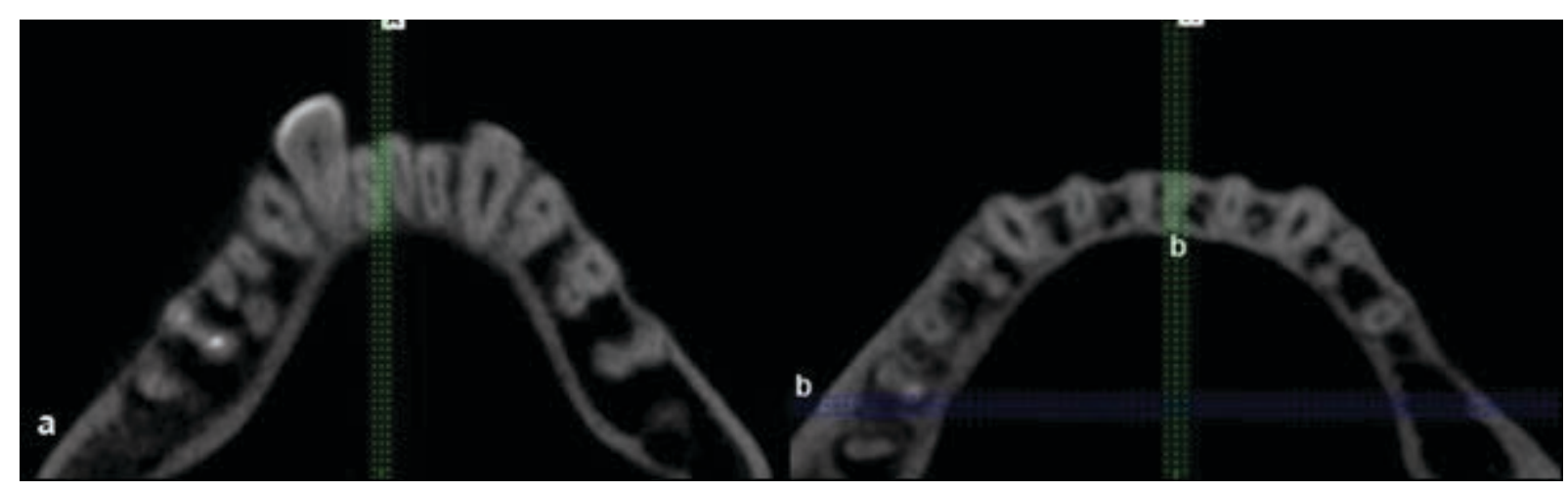

Figure 2. Axial plan. (a) Three Roots Premolar. (b) Two Roots Premolar.

Table 2. Root Canal Classification of First and Second Premolars According to Age Groups

\begin{tabular}{|c|c|c|c|c|c|c|c|c|c|c|c|c|c|c|c|c|c|}
\hline & & \multicolumn{14}{|c|}{ Age } & \multicolumn{2}{|c|}{ Chi-square test } \\
\hline & & \multicolumn{2}{|c|}{$\leq 20$ age } & \multicolumn{2}{|c|}{ 21-30 age } & \multicolumn{2}{|c|}{$31-40$ age } & \multicolumn{2}{|c|}{$41-50$ age } & \multicolumn{2}{|c|}{ 51-60 age } & \multicolumn{2}{|c|}{$\geq 61$ age } & \multicolumn{2}{|c|}{ Total } & \multirow[t]{2}{*}{ Chi-square } & \multirow[t]{2}{*}{$\mathbf{p}$} \\
\hline & & $\mathbf{n}$ & $\%$ & $\mathbf{n}$ & $\%$ & $\mathbf{n}$ & $\%$ & n & $\%$ & $\mathbf{n}$ & $\%$ & $\mathbf{n}$ & $\%$ & $\mathbf{n}$ & $\%$ & & \\
\hline \multirow{4}{*}{$\begin{array}{l}\text { First premolar } \\
\text { root canal } \\
\text { classification }\end{array}$} & Type I & 100 & 81.3 & 136 & 77.27 & 111 & 88.1 & 95 & 92.23 & 80 & 96.39 & 36 & 94.74 & 558 & 85.98 & \multirow{4}{*}{31.055} & \multirow{4}{*}{0.001} \\
\hline & Type III & 2 & 1.63 & 6 & 3.41 & 2 & 1.59 & 0 & 0 & 2 & 2.41 & 1 & 2.63 & 13 & 2 & & \\
\hline & Type V & 21 & 17.07 & 34 & 19.32 & 13 & 10.32 & 8 & 7.77 & 1 & 1.2 & 1 & 2.63 & 78 & 12.02 & & \\
\hline & Total & 123 & 100 & 176 & 100 & 126 & 100 & 103 & 100 & 83 & 100 & 38 & 100 & 649 & 100 & & \\
\hline \multirow{4}{*}{$\begin{array}{l}\text { Second } \\
\text { premolar } \\
\text { root canal } \\
\text { classification }\end{array}$} & Type I & 117 & 99.15 & 157 & 98.13 & 125 & 99.21 & 92 & 100 & 64 & 96.97 & 38 & 100 & 593 & 98.83 & \multirow{4}{*}{$*$} & \multirow{4}{*}{0.789} \\
\hline & Type III & 0 & 0 & 2 & 1.25 & 0 & 0 & 0 & 0 & 1 & 1.52 & 0 & 0 & 3 & 0.5 & & \\
\hline & Type V & 1 & 0.85 & 1 & 0.63 & 1 & 0.79 & 0 & 0 & 1 & 1.52 & 0 & 0 & 4 & 0.67 & & \\
\hline & Total & 118 & 100 & 160 & 100 & 126 & 100 & 92 & 100 & 66 & 100 & 38 & 100 & 600 & 100 & & \\
\hline
\end{tabular}


There was no statistically significant relationship between the age groups and the root canal of the second premolars ( $p>0.05$ ). Although statistically not significant, the root canal classification of $99.15 \%$ of the participants at the age of $\leq 20,98.13 \%$ of those at the age of 21 to 30 , $99.21 \%$ of those at the age of 31 to $40,100 \%$ of those at the age of 41 to $50,96.97 \%$ of those at the age of 51 to 60 , and $100 \%$ of those at the age of $\geq 61$ were of Type I (Table 2).

\section{Discussion}

Many researchers used different methods to analyze anatomical variations of root canal morphologies ${ }^{3,10}$. The methods frequently used in the examination of root canal morphologies can be listed as hard tissue section, root canal dyes, conventional radiography, CBCT or in vitro micro-CT scanning. In the present study, the morphology of the mandibular premolars was studied using CBCT. It is a three-dimensional non-invasive imaging technique that facilitates the diagnosis of root anatomy and root canal morphology by taking sections from each tooth in different directions ${ }^{11,12}$. Neelakantan et al. reported that CBCT provided more effective and reliable results than other analysis methods in the evaluation of root canal morphologies ${ }^{13}$.

In the literature, there are studies evaluating the root canal morphology of mandibular premolars in terms of gender. In some studies, gender-related differences were reported ${ }^{14,15}$. On the other hand, there are studies indicating that gender does not have any impact on root canal morphology and symmetry ${ }^{16,17}$. The results of those studies are in parallel with the results of the present study. The differences may result from different sample sizes and ethnic or regional background of the participants included.

Symmetry in the morphologies of the teeth on the same jaw are critical for guiding clinicians. In the literature, there are limited data on this subject. In a study conducted in the Turkish population, Ok et al. reported anatomical differences in the symmetrical upper premolars; however, they did not state the rate of the symmetry ${ }^{15}$. Keçeci et al. reported that $89.29 \%$ of the first premolars in women and $81.82 \%$ of those in men were symmetrical and that $89.29 \%$ and $95.45 \%$ of the second premolars in women and men, respectively, were symmetrical $^{18}$. The rate of the symmetry teeth was found to be high in general. Based on these results, the symmetry in the morphology of mandibular premolars were analyzed in the present study. It was observed in our study that $88.89 \%$ of 297 mandibular first premolars and $98.45 \%$ of 258 mandibular second premolars were symmetrical. There was no statistically significant relationship between the gender and age groups in the symmetrical teeth $(\mathrm{p}>0.05)$.
The most common root canal classification in mandibular first and second premolars is Vertucci Type I. In the literature, the studies conducted in the Turkish population showed Type I incidence rates of $92.8 \%-91.4 \%$ and $98.5-98.1 \%$ for the mandibular first and second premolars, respectively ${ }^{15,16}$. In the present study, it was observed that $85.98 \%$ of the first premolar and $98.83 \%$ of the second premolars were into Type I canal classification The results of the present study are in parallel with other studies performed on similar populations for the second premolars. In our study, the incidence of Type I canal in the first premolar teeth was consistent with previous studies regarding the groups including participants at the age of 41 to $50(92.23 \%), 51$ to $60(96.39 \%)$, and $\geq$ $61(94.74 \%)$. The incidence of Type I canal, on the other hand, was lower in the groups including individuals at the age of 31 to $40(88.1 \%), 21$ to $30(77.27 \%)$, and $\leq 20$ $(81.3 \%)$. In the study on mandibular molar teeth, Hess stated that the differentiation of root canals occured after root development was completed ${ }^{19}$. Canal differentiation in the first and second molar teeth is completed approximately three to six and two to six years, respectively, following the root development. Moreover, a mixed canal morphology is observed in the first and second molars between the ages of 12 to 20 and 16 to 30, respectively. Therefore, these periods seems as a transition period for channel differentiation. The root development of mandibular premolar teeth is completed aproximately at the same age range as mandibular molar teeth. The changing rates in Type I configuration in the present study may result from the incomplete canal differentiation in mandibular first premolar teeth of the participants at the age of $<40$. In another study, it was also reported that canal differentiation of the first and second molars was completed at around the age of 30 to $40^{20}$. Therefore, in the present study, an increase in the incidence rate of Type I canal configuration may have been observed starting from the age of 41 . Treatments should accordingly be planned, considering that different root canal anatomies may be encountered in the treatment of mandibular first premolars.

\section{Conclusions}

Root canal configuration of mandibular premolar teeth is usually Vertucci Type I. Mandibular first premolars were more of Type III and Type V canal structures compared to the second premolars. Mandibular second premolar teeth $(98.45 \%)$ were more symmetrical than mandibular first premolar teeth $(88.89 \%)$. There was no relationship between gender and root canal configuration in mandibular premolars. In the first premolars, there was an increase in the incidence rate of Type I canals as the participants got older. 


\section{References}

1. Blicher B, Torabinejad M, Walton RE. Endodontic Diagnosis and Treatment Planning. In: Torabinejad M, Fouad A, Shabahang S editors. Endodontics E-Book: Principles and Practice. Elsevier Health Sciences; 2020. pp: 61-83.

2. Slowey R. Root canal anatomy: road map to successful endodontics. Dent Clin North Am, 1979;23:555-573.

3. Pineda F, Kuttler Y. Mesiodistal and buccolingual roentgenographic investigation of 7,275 root canals. Oral Surg Oral Med Oral Pathol Oral Radiol, 1972;33:101-110.

4. Vertucci FJ. Root canal anatomy of the mandibular anterior teeth. J Am Dent Assoc, 1974;89:369-371.

5. Green D. Double canals in single roots. Oral Surg Oral Med Oral Pathol, 1973;35:689-696.

6. Tachibana H, Matsumoto K. Applicability of X-ray computerized tomography in endodontics. Dent Traumatol, 1990;6:16-20.

7. Patel S, Dawood A, Ford TP, Whaites E. The potential applications of cone beam computed tomography in the management of endodontic problems. Int Endod J, 2007;40:818-830

8. Neelakantan P, Subbarao C, Ahuja R, Subbarao CV, Gutmann JL. Cone-beam computed tomography study of root and canal morphology of maxillary first and second molars in an Indian population. J Endod, 2010;36:16221627.

9. Zhang R, Yang $\mathrm{H}$, Yu X, Wang H, Hu T, Dummer PMH. Use of CBCT to identify the morphology of maxillary permanent molar teeth in a Chinese subpopulation. Int Endod J, 2011;44:162-169.

10. Çalişkan MK, Pehlivan Y, Sepetcioğlu F, Turkun M, Tuncer SS. Root canal morphology of human permanent teeth in a Turkish population. J Endod, 1995;21:200-204.

11. Fan B, Yang J, Gutmann JL, Fan M. Root canal systems in mandibular first premolars with $\mathrm{C}$-shaped root configurations. Part I: Microcomputed tomography mapping of the radicular groove and associated root canal cross-sections. J Endod, 2008;34:1337-1341.

12. Tsiklakis K, Donta C, Gavala S, Karayianni K, Kamenopoulou V, Hourdakis CJ. Dose reduction in maxillofacial imaging using low dose Cone Beam CT. Eur J Radiol, 2005;56:413-417.

13. Neelakantan P, Subbarao C, Subbarao CV. Comparative evaluation of modified canal staining and clearing technique, cone-beam computed tomography, peripheral quantitative computed tomography, spiral computed tomography, and plain and contrast medium-enhanced digital radiography in studying root canal morphology. J Endod, 2010;36:1547-1551.
14. Sert S, Bayirli GS. Evaluation of the root canal configurations of the mandibular and maxillary permanent teeth by gender in the Turkish population. J Endod, 2004;30:391-398.

15. Ok E, Altunsoy M, Nur BG, Aglarci OS, Çolak M, Güngör E. A cone-beam computed tomography study of root canal morphology of maxillary and mandibular premolars in a Turkish population. Acta Odontol Scand, 2014;72:701-706.

16. Guneşer MB, Unver T. Prevalence of bilateral symmetry in root and root canal anatomy of mandibular premolars: a cone beam computed tomography study. Clin Dent Res, 2016;40:66-72.

17. Miyoshi S, Fujiwara J, Tsuji YH, Nakata T, Yamamoto K. Bifurcated root canals and crown diameter. J Dent Res, 1977;56:14-25.

18. Keçeci A D, Gormez O, Kaya B U. Batı Akdeniz popülasyonunda üst küçük azı dişlerinin kök ve kanal morfolojilerinin konik 1şınlı bilgisayarlı tomografi yardımıyla değerlendirilmesi. Türkiye Klinikleri J Dental Sci, 2015;1:47-52.

19. Hess W, Zurcher E. The Anatomy of the Root-Canals of the Teeth of the Permanent Dentition. John Bale Sons and Danielsson. London, 1925. pp: 4-49.

20. Peiris H, Pitakotuwage T, Takahashi M, Sasaki K, Kanazawa E. Root canal morphology of mandibular permanent molars at different ages. Int Endod J, 2008;41:828-835.

Conflict of Interests: Nothing to declare.

Financial Disclosure Statement: Nothing to declare.

Human Rights Statement: All the procedures on humans were conducted in accordance with the Helsinki Declaration of 1975, as revised 2000. Consent was obtained from the patient/s and approved for the current study by national ethical committee.

Animal Rights Statement: None required.

Received on January 22, 2021.

Revised on March 12, 2021.

Accepted on May 29, 2021.

\section{Correspondence}

\section{Güney Mustafa YÜZER}

Department of Endodontics, Faculty of Dentistry, Dicle University Diyarbakir/ Turkey

e-mail:guneymustafayuzer@gmail.com 